More recently, Sir Paul Nurse, Harveian Orator in 2003, suggested that future studies of the cell might need to move away from biology to the disciplines of mathematics and physics. ${ }^{7}$ In contemporary research, Sir Keith Peters described the career of an academic Cambridge respiratory physician who trained in a haematology department but is now making major contributions to dementia research 'which he is currently pursuing in the department of genetics by introducing mutated neuroserpin genes into flies. ${ }^{4}$

\section{Research environment}

The appropriateness of the research environment is obviously essential, both in the academic and the NHS environment, but there can be no single model. A close physical relationship between academic clinical departments and those in basic science is obviously right: no-one would believe that a failed orthopaedic surgeon (Frederick Banting) and a medical student (Charles Best) could have discovered insulin had it not been for the state-of-the-art laboratories of JJR McLeod and the collaboration with the chemist, JB Collip. ${ }^{8}$ In contemporary terms, Sir Keith Peters has described the sophisticated research links in Cambridge. ${ }^{4}$ But much less consideration is given to the relationships between appropriate clinical departments which can create such an important stimulus: the juxtaposition of clinical departments can be the key to cross fertilisation of ideas and at the same time offer the best treatment for patients. The close association of a diabetes unit, for example, with ophthalmologists, neurologists, renal physicians, or obstetricians leads at times to highly innovative observations and programmes of clinical research, often following joint consultations over individual patients. ${ }^{9}$

\section{The future for NHS research}

Sir Walter Bodmer, in his 1996 Harveian Oration, pleaded that 'we must at least ensure that the opportunity to do the firstclass clinical research in the setting of our NHS is preserved.' ${ }^{10}$ Now there are encouraging signs. Following a report from the Research for Patient Benefit Working Party, the UK Clinical Research Collaboration (UKCRC) was created to oversee 'the effective and efficient translation of scientific advances into patient care. ${ }^{11}$ R\&D funding has now been expanded by some $£ 100$ million over four years to assist with the establishment of managed research networks in the NHS. Cancer and mental health networks already exist, and there are now proposals for networks in diabetes, ${ }^{12}$ stroke, ${ }^{13}$ Alzheimer's disease, and medicines for children. These networks will establish collaborative infrastructures individually tailored by the specialty to promote advances in treatment.

Almost 100 years ago, the doyen of clinical research, Sir Thomas Lewis, wrote 'there is indeed a fertile science that deals primarily with patients and this must be encouraged to a more vigorous growth. ${ }^{14}$ Commentators today are saying exactly the same, and much encouragement for academic clinical medicine comes with the report from the Forum on Academic
Medicine,${ }^{15}$ described in our last issue, ${ }^{16}$ with its strong recommendations on flexibility in training. In the USA, a substantial boost to morale in clinical research has come from the opening of a 242-bed research unit at the National Institutes of Health in Bethesda. But at the same time, we must not lose the enthusiasm of individual clinical research workers in the NHS fired up for the chase - the chase of ideas.

\section{References}

1 Pyke DA. One hundred years of clinical science: a view from the United Kingdom. Trans Assn Am Physicians 1986;99:ccxlviii-cclx.

2 Feldberg WS. Fifty years on: looking back on some developments in neurohumoral physiology. The Sherrington Lectures XVI. Liverpool: Liverpool University Press, 1982.

3 Brockman J (ed). Curious minds: how a child becomes a scientist. New York: Pantheon, 2004.

4 Peters K. Exceptional Matters: clinical research from bedside to bench. Clin Med 2004;4:551-66.

5 Warlow C. Over-regulation of clinical research: a threat to public health. Clin Med 2005;5:33-5.

6 Porter R. The greatest benefit to mankind. London: HarperCollins, 1997.

7 Nurse P. The great ideas of biology. Clin Med 2003;3:560-68.

8 Bliss M. The discovery of insulin. Edinburgh: Paul Harris, 1983.

9 Watkins PJ. The enigma of autonomic failure in diabetes. J $R$ Coll Physicians Lond 1998;32:360-65.

10 Bodmer WF. The somatic evolution of cancer. The Harveian Oration of 1996. J R Coll Physicians Lond 1996;31:82-9.

11 Department of Health. Research for Patient Benefit Working Party: final report. London: HMSO, 2004.

12 Heller S, Kinmouth AL. A clinical research network in diabetes for the UK. Diabet Med 2004;21:1061-3.

13 Forster A, Young J. Research networks for stroke rehabilitation: opportunities and barriers. Clin Med 2005;5:42-6.

14 Lewis T. Research in medicine: its position and its needs. BMJ 1930;1:479-83.

15 Royal College of Physicians. Clinical academic medicine: the way forward. Report from the Forum on Academic Medicine. London: RCP, 2004

16 Pusey C, Thakker R. Clinical academic medicine: the way forward. Clin Med 2004;4:483-8.

\section{Tsunami}

A wall of water arising from an earthquake under the Indian Ocean has caused death and destruction on an unprecedented scale. The human spirit across the globe has risen to assist those who are now suffering, showing unparalleled generosity and often unstinting devotion offered at great personal sacrifice. It has been moving to witness the untiring efforts of doctors attending the sick and injured round the clock in daunting conditions. Our sympathy goes out to the bereaved, and our admiration to those who are caring for them. We would like our own Fellows and Members to know that this College will do all in its power to support them, and that it is setting up a RCP Tsunami Relief Fund with the aim of helping to restore the medical structure in affected countries. 